\title{
Exogenous nitric oxide inhibits IRS-1 expression in rat hepatocytes and skeletal myocytes
}

\author{
Simone Badal, Paul D. Brown* \& Dalip Ragoobirsingh \\ Department of Basic Medical Sciences (Biochemistry section), University of the West Indies, Kingston, \\ Jamaica
}

Received 20 June 2005; accepted 12 January 2006

(c) 2006 National Science Council, Taipei

Key words: 2-(4-carboxyphenyl)-4,4,5,5-tetramethylimidazoline-1-oxyl 3-oxide (carboxy-PTIO), insulin receptor substrate-1, Nitric oxide, S-nitroso-N-acetylpenicillamine (SNAP), S-nitrosoglutathione (GSNO), signal transduction

\begin{abstract}
Summary
Accumulative evidence has supported the role of nitric oxide (NO) in a variety of normal physiological functions as well as many pathological conditions. In this study, we examined the possible diabetogenicity of NO by measuring the expression of the insulin receptor substrate (IRS)-1 in rat hepatocytes and skeletal myocytes. IRS- 1 is important in the insulin-mediated signal transduction pathway in both liver and skeletal muscle. Exogenous NO donated by S-nitroso-N-acetylpenicillamine (SNAP) and S-nitrosoglutathione (GSNO) resulted in significant reduction in levels of IRS-1 in both cells, when compared to the insulinstimulated control $(p<0.001)$. Reversal to near normal levels was achieved using the NO scavenger 2-(4-carboxyphenyl)-4,4,5,5-tetramethylimidazoline-1-oxyl 3-oxide (carboxy-PTIO). SNAP was the more potent drug, and the skeletal myocytes were the more sensitive cells to the inhibitory effects of NO released from the drugs. These results provide further evidence that exogenous NO is a potent modulator of insulinmediated signal transduction and may play a significant role in the pathogenesis of type 2 diabetes mellitus.
\end{abstract}

\section{Introduction}

Type 2 diabetes is a heterogeneous disorder characterized by at least two pathological defects, namely $\beta$ cell dysfunction and insulin resistance [1, 2]. Both skeletal muscle and liver are important targets for insulin action, and insulin resistance in skeletal muscle is a characteristic feature of type 2 diabetes [3].

Insulin is the principal hormone controlling blood glucose and acts by stimulating glucose influx and metabolism in muscle and adipocytes and inhibiting gluconeogenesis by the liver [4]. Insulin action is mediated through the insulin receptor, a

*To whom correspondence should be addressed. Tel.: 876-9272290; Fax: 876-977-7852; E-mail: paul.brown@uwimona.edu.jm transmembrane glycoprotein with intrinsic protein tyrosine kinase activity [4]. The level of tyrosine kinase reflects the serum concentration of insulin and appears to mediate the insulin response through tyrosine phosphorylation of the receptor itself and substrates like insulin receptor substrate (IRS)-1 [5-7]. IRS- 1 contains 21 potential tyrosine phosphorylation sites, of which at least eight undergo phosphorylation by the activated receptor [4].

Nitric oxide is a short lived free radical gas and biological signalling molecule produced by the intracellular enzyme NO synthase [8]. The reactivity of NO towards molecular oxygen, thiols, transition metal centres, and other biological targets enables NO to act as a ubiquitous cellsignalling molecule with diverse physiological and pathological roles $[8,9]$. In this regard, NO can 
react with thiols to form S-nitrosothiols in vivo, such as S-nitrocysteine and S-nitrosoglutathione (GSNO), although the mechanism of this reaction remains unclear [10].

Nitric oxide drugs are useful in the treatment of several disorders, and are generally indicated in cases of NO insufficiency. Previously, we have established that exogenous NO (from NO-releas ing drugs) inhibited in vivo insulin binding to its receptor on erythrocytes and mononuclear leukocytes [11], and in vitro glucose uptake in skeletal muscle cells [12] and adipocytes [13]. Our current objective was to characterize the in vitro effects of exogenous NO generated by S-nitroso- $\mathrm{N}$-acetyl penicillamine (SNAP) and S-nitrosoglutathione (GSNO) on expression of IRS-1 in isolated rat hepatocytes and skeletal myocytes.

\section{Materials and methods}

\section{Chemicals and reagents}

Anti-insulin receptor substrate (IRS)-1 and associated alkaline phosphatase conjugate were obtained from Chemicon International Inc. (Temecula, CA, USA). All biochemicals and enzymes were of analytical grade and were purchased from commercial suppliers.

\section{Preparation of dissociated cells}

Female and male Sprague-Dawley rats (6-8-weeks old weighing 200-300 g) were housed at the University of the West Indies Preclinical Animal House, Mona, Jamaica, with free access to water and food. Food was withdrawn on the evening prior to experimentation and rats were euthanatized using diethyl ether. The ethics committee of the University of the West Indies/University Hospital of the West Indies approved the experiments involving animals and method of euthanasia.

Approximately $5-10 \mathrm{~g}$ of liver and skeletal muscle tissue were aseptically removed, washed 2-3 times with sterile phosphate buffered saline (PBS, pH 7.2) and minced using a sterile scalpel. Hepatocytes and skeletal myocytes were isolated using a modification of the method by Freshney [14]. Briefly, minced tissues were incubated in Krebs' Ringer Bicarbonate (KRB) containing $200 \mathrm{U} / \mathrm{ml}$ collagenase, $10 \%$ bovine serum albumin
(BSA) and $1 \times$ penicillin/streptomycin/neomycin (PSN) (Sigma, St. Louis, MO, USA) at $37^{\circ} \mathrm{C}$ in a humidified incubator containing $95 \%$ air and $5 \% \mathrm{CO}_{2}$. Dissociated cells were collected by centrifugation at $100 \mathrm{rpm}$ for $5 \mathrm{~min}$, washed twice in $5 \mathrm{ml} \mathrm{KRB}$ buffer containing $2.5 \mathrm{mM}$ glucose and $2 \%$ BSA and resuspended in $20-30 \mathrm{ml} \mathrm{KRB}$ without any additives. Viability of dissociated cells was verified using Trypan blue.

\section{Treatments of dissociated cells}

After an incubation period of $30 \mathrm{~min}$, cells $(1 \mathrm{ml}$ packed cells $/ 1.5 \mathrm{ml}$ Eppendorf tube) were treated with 25 and $50 \mathrm{ng} / \mathrm{ml}$ SNAP or GSNO (Sigma), in the absence or presence of 100 or $1000 \mathrm{nM}$ insulin at $37^{\circ} \mathrm{C}$ for $1 \mathrm{~h}$. Nitric oxide released from the drugs was determined as nitrite using the Greiss reagent (BDH, Poole, UK). Experiments with $25 \mathrm{ng} / \mathrm{ml}$ GSNO and SNAP were repeated in the presence of $0.1 \mu \mathrm{M}$ of the NO scavenger, 2-(4-carboxyphenyl)4,4,5,5-tetramethylimidazoline-1-oxyl 3-oxide (carboxy-PTIO; Sigma).

\section{Immunoblotting}

Cells were washed and solubilized in $750 \mu \mathrm{l}$ of $1 \%$ Triton X-100 lysis buffer in the presence of protease inhibitors for $30 \mathrm{~min}$ at $37^{\circ} \mathrm{C}$. The protein content of cell lysates was determined using the Bradford method [15]. Protein samples $(30-50 \mu \mathrm{g})$ in $25 \mu \mathrm{l}$ of lysis buffer were applied to PVDF membrane using a manifold apparatus (Scie-Plas, Warwickshire, UK) and a vacuum pressure pump (Barnant Co., USA). Blots were probed with anti-IRS-1 antibodies (1:1000) followed by the alkaline phosphatase conjugated secondary antibody and developed according to the manufacturer's instructions (Kirkegaard and Perry Laboratories, Gaithersburg, MD, USA). Membranes were scanned and densitometric analysis carried out using NIH Image $\mathbf{J}$ programme for PC [16].

\section{Statistical analysis}

Statistical analysis was performed using either unpaired Student's $t$ test or ANOVA (Fisher, multiple comparisons), as applicable. Values are presented as means \pm S.E.M. of 3-6 observations, 
and differences among means were considered significant at $p<0.05$.

\section{Results}

Nitric oxide released from drugs

Figure 1 shows the concentration-dependent increase in nitric oxide (measured as nitrite) released from SNAP and GSNO in aqueous solution. In all cases there was a gradual increase in NO released, with a greater amount of NO being released from drugs at the higher concentration. Carboxy-PTIO, when added either at the start of the experiment or after $30 \mathrm{~min}$ resulted in a sharp decline in the amount of NO released from either drug (Figure 2).

Effect of NO released from SNAP and GSNO on IRS-1 expression in hepatocytes and skeletal myocytes

The inhibitory effects of NO released from SNAP and GSNO on IRS-1 expression in isolated rat
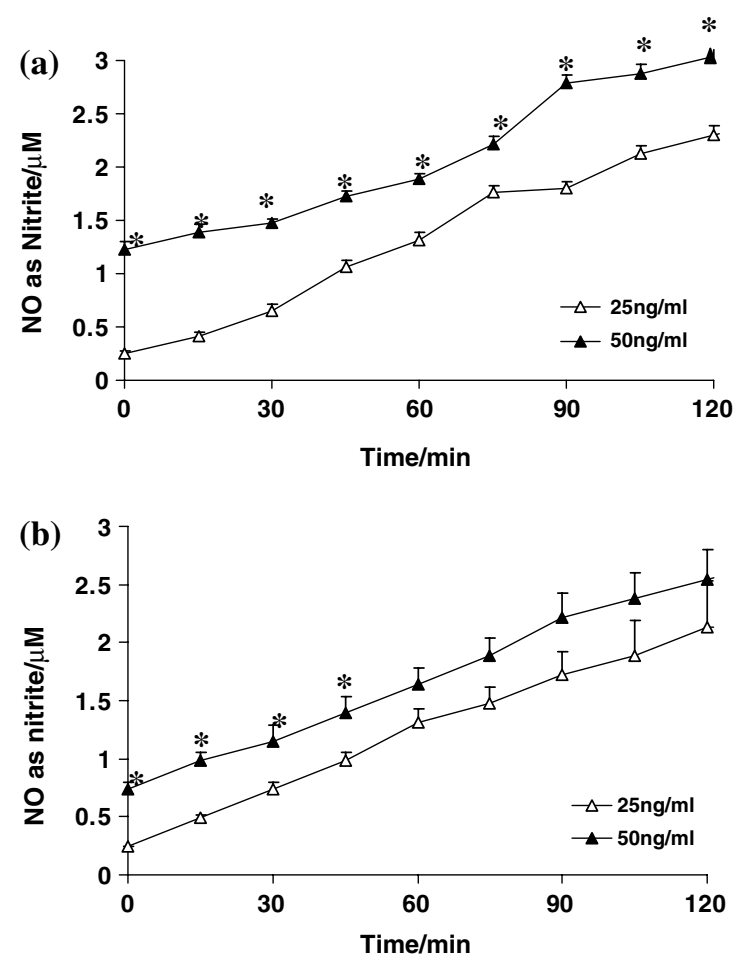

Figure 1. Nitric oxide (NO) released from (a) SNAP and (b) GSNO at 25 and $50 \mathrm{ng} / \mathrm{ml}$. Values are expressed as means \pm $\mathrm{SEM} ;{ }^{*} p<0.05$ vs the drug at $25 \mathrm{ng} / \mathrm{ml}$. hepatocytes and skeletal myocytes are shown in Figures 3 and 4. The mean basal (unstimulated) expression or content of IRS-1 in rat hepatocytes was $51.70 \pm 10.85 \%$ when compared to the insulinstimulated control (insulin at $100 \mathrm{nM}$ ), which was normalized to $100 \%$ (Figure 3). Incubation with SNAP at the concentrations studied significantly decreased expression of IRS-1 compared to the insulin-stimulated control by $60-100 \%$ $(p<0.01)$. Total inhibition of IRS-1 expression occurred when cells were incubated with $25 \mathrm{ng} / \mathrm{ml}$ SNAP in the presence of $100 \mathrm{nM}$ insulin. By comparison, in treatments with $50 \mathrm{ng} / \mathrm{ml}$ SNAP, expression of IRS-1 was $19-43 \%$ of the insulinstimulated control, indicating that there was a greater inhibition at the lower concentration, especially in the presence of $100 \mathrm{nM}$ insulin. Further, SNAP at $50 \mathrm{ng} / \mathrm{ml}$ decreased basal expression of IRS-1 over that of $25 \mathrm{ng} / \mathrm{ml}$. Generally, reduction of IRS-1 content by SNAP was to the extent of the basal cellular levels, or to that in the presence of high $(1000 \mathrm{nM})$ insulin. In the absence of insulin, there was no significant difference in the effect of SNAP at either concentration $(p>0.05)$.

Generally, GSNO had a greater effect in reducing IRS-1 expression in these hepatocytes, although not significantly different from that with SNAP. Except for $25 \mathrm{ng} / \mathrm{ml}$ GSNO in the presence of $100 \mathrm{nM}$ insulin, the reduction in IRS-1 expression was significantly lower than that of the basal levels. Further, in treatments with 25 or $50 \mathrm{ng} / \mathrm{ml}$ GSNO, reductions in the content of cellular IRS-1 was to $13-40 \%$ or $21-27 \%$ of the insulin-stimulated control, respectively $(p<0.01)$.

In the absence of insulin, there was also no significant difference in the effects of GSNO at either concentration $(p>0.05)$.

The mean basal expression of IRS-1 in rat skeletal myocytes was $54.34 \pm 7.58 \%$ of the $100 \mathrm{nM}$ insulin-stimulated control (Figure 4). Incubation with SNAP at either concentration significantly reduced IRS-1 expression in these cells $(p<0.01$; Figure 4). However, $25 \mathrm{ng} / \mathrm{ml}$ SNAP had a slightly greater effect than $50 \mathrm{ng} / \mathrm{ml}$ SNAP in reducing IRS- 1 expression in the absence $(10.74 \pm 1.98 \%$ versus $12.70 \pm 1.23 \%)$ or presence of $100 \mathrm{nM}$ insulin $(6.03 \pm 0.98 \%$ versus $11.72 \pm$ $1.40 \%)$. These differences were significant only in the presence of $100 \mathrm{nM}$ insulin $(p<0.05)$. Further, $50 \mathrm{ng} / \mathrm{ml}$ SNAP caused a marginally (though 



Figure 2. Nitric oxide (NO) released from (a and b) SNAP and (c and d) GSNO at 25 and $50 \mathrm{ng} / \mathrm{ml}$ in the presence of the NOscavenger, carboxy-PTIO, added at time $0 \mathrm{~min}(\mathrm{a}$ and b) and after $30 \mathrm{~min}$ (c and d).

not significantly) greater reduction than $25 \mathrm{ng} / \mathrm{ml}$ SNAP in expression of IRS-1 in the presence of $1000 \mathrm{nM}$ insulin $(7.23 \pm 0.75 \%$ versus $8.20 \pm$ $1.06 \% ; p>0.05)$.

Both concentrations of GSNO (Figure 4) were effective in reducing IRS- 1 expression $(p<0.05)$. However, $25 \mathrm{ng} / \mathrm{ml}$ GSNO compared to $50 \mathrm{ng} / \mathrm{ml}$ GSNO was more effective in reducing IRS-1 content in the absence $(14.79 \pm 3.12 \%$ versus $34.22 \pm 8.90 \%)$ or presence of $100 \mathrm{nM}$ insulin $(4.37 \pm 1.03 \%$ versus $41.49 \pm 9.02 \% ; p<0.05)$. There was no significant difference between the effects of 25 or $50 \mathrm{ng} / \mathrm{ml} \mathrm{GSNO}$ on IRS- 1 content in the presence of $1000 \mathrm{nM}$ insulin $(12.89 \pm 2.56 \%$ versus $12.30 \pm 3.05 \%$ ).

Generally, in the presence of $100 \mathrm{nM}$ insulin, $25 \mathrm{ng} / \mathrm{ml}$ GSNO was more potent than $25 \mathrm{ng} / \mathrm{ml}$ SNAP in reducing IRS-1 expression $(p<0.001)$, and a greater reduction was observed for $50 \mathrm{ng} / \mathrm{ml}$ SNAP in the absence or presence of insulin when compared to $50 \mathrm{ng} / \mathrm{ml} \mathrm{GSNO}(p<0.002)$. However, the general observation was $25 \mathrm{ng} / \mathrm{ml}$ SNAP effected a greater overall reduction of IRS-1 expression in skeletal myocytes.

We tested whether the NO scavenger, carboxyPTIO was able to reverse the effect of NOmediated reduction in expression of IRS-1 in the hepatocytes and skeletal myocytes. We found a near normal expression of IRS-1 in hepatocytes co-treated with carboxy-PTIO and $25 \mathrm{ng} / \mathrm{ml}$ SNAP or GSNO in the presence of $100 \mathrm{nM}$ insulin $(87.5 \pm 1.6 \%$ versus $93.0 \pm 0.0 \%)$ or $1000 \mathrm{nM}$ insulin $(76.8 \pm 1.1 \%$ versus $75.0 \pm 0.9 \%$; Figure 5$)$. These were not significantly different from the respective controls with 100 or $1000 \mathrm{nM}$ insulin $(p>0.8)$.

A similar effect was seen in skeletal myocytes exposed to $25 \mathrm{ng} / \mathrm{ml} \mathrm{SNAP}$ or GSNO when the NO scavenger carboxy-PTIO was added in the presence of $100 \mathrm{nM}$ insulin $(97.80 \pm 0.60 \%$ versus $85.96 \pm 0.18 \%)$ and $1000 \mathrm{nM}$ insulin $(73.60 \pm$ $4.34 \%$ versus $43.50 \pm 4.67 \%$; Figure 5). These were not significantly different from the respective controls with 100 or $1000 \mathrm{nM}$ insulin $(p>0.2)$. 

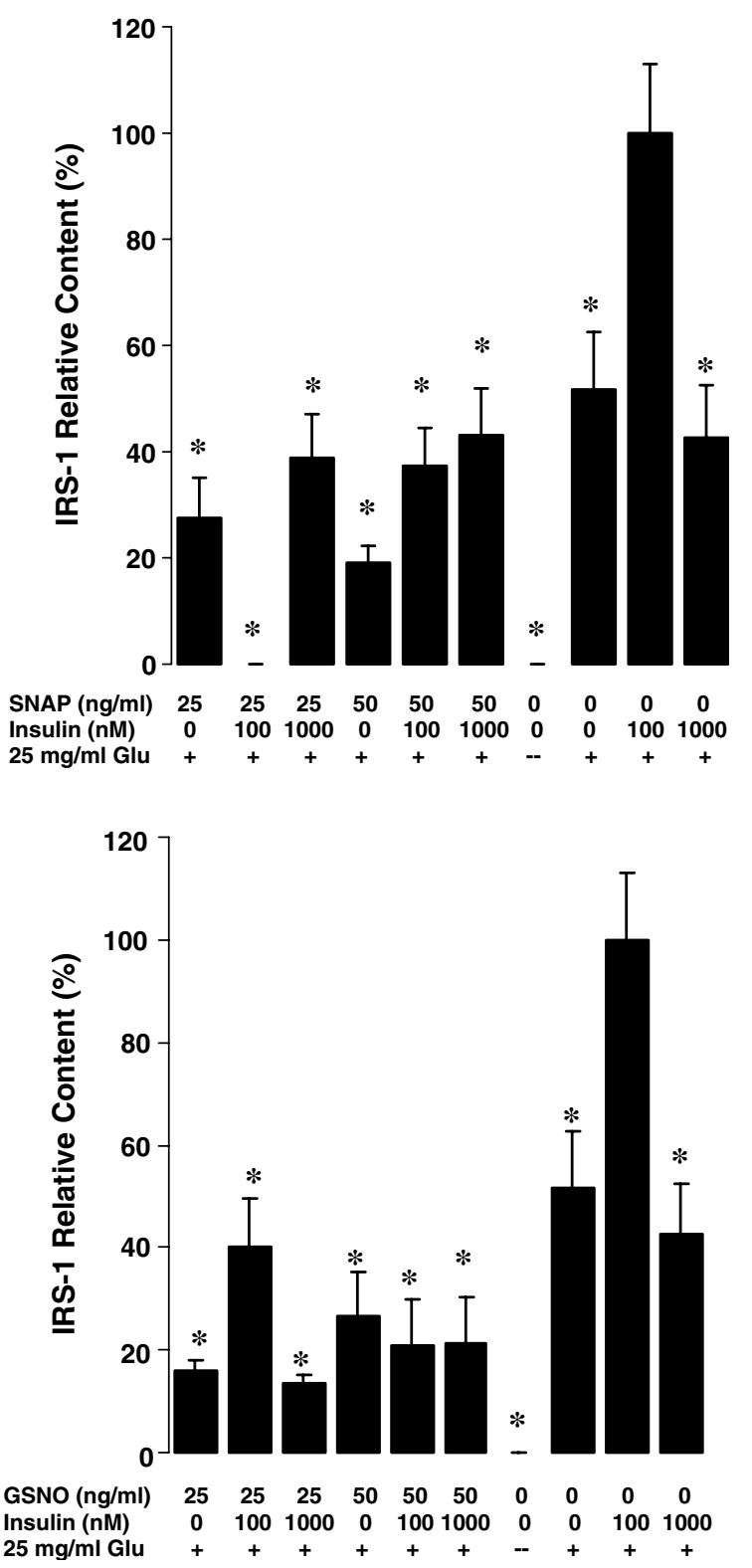

Figure 3. The effects of NO donor on content of IRS-1 in rat hepatocytes. Rat hepatocytes were treated with the indicated concentrations of (a) SNAP, (b) GSNO, in the presence the indicated concentrations of insulin, with or without $25 \mathrm{mg} / \mathrm{ml}$ glucose (Glu). Values are expressed as means \pm SEM; ${ }^{*} p<0.05$ vs the insulin-stimulated control (100 mM insulin).

\section{Discussion}

The major conclusion to be drawn from this study is that the pathophysiologically relevant concentrations of NO are sufficient to reduce the expression, and hence availability, of IRS-1 in two
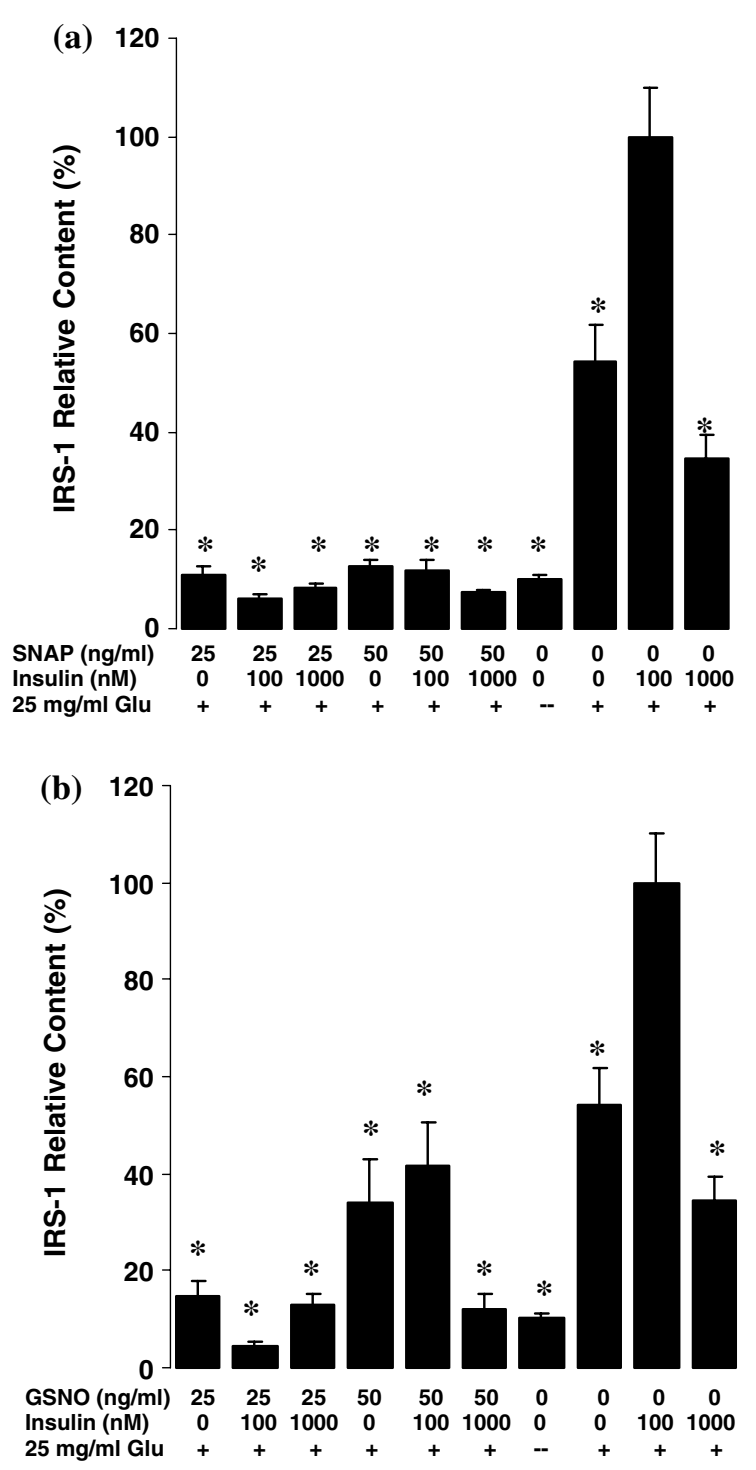

Figure 4. The effects of NO donor on content IRS-1 in rat skeletal myocytes. A, Rat skeletal myocytes were treated with the indicated concentrations of (a) SNAP, (b) GSNO, in the presence the indicated concentrations of insulin, with or without $25 \mathrm{mg} / \mathrm{ml}$ glucose (Glu). Values are expressed as means \pm SEM; ${ }^{*} p<0.05$ vs the insulin-stimulated control $(100 \mathrm{mM}$ insulin).

insulin-sensitive tissues. We found that rat hepatocytes and skeletal myocytes treated with SNAP or GSNO had significantly reduced IRS- 1 content. Further, the fact that we were could completely abrogate the inhibitory effects of both drugs with the NO scavenger, carboxy-PTIO, where drugs had varying effects in the two tissues, suggests that the effects of SNAP and GSNO were related to the generation of $\mathrm{NO}$ and not to a non-specific effect 

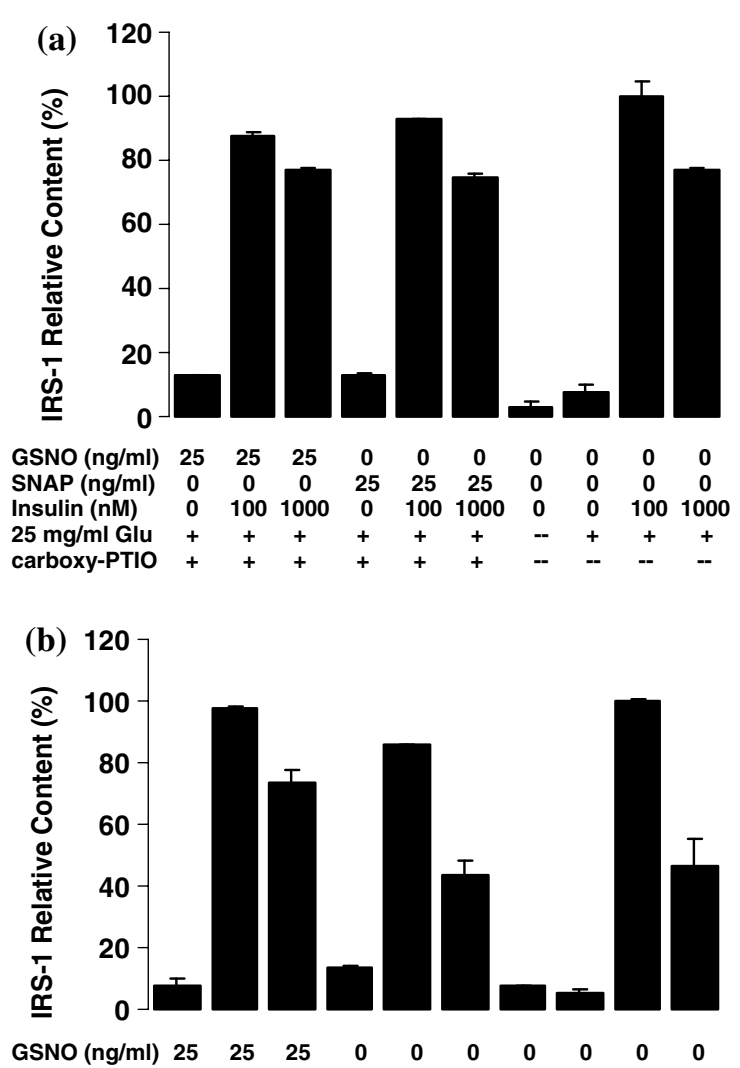

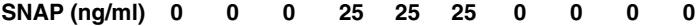
$\begin{array}{lllllllllll}\text { Insulin (nM) } & 0 & 100 & 1000 & 0 & 100 & 1000 & 0 & 0 & 100 & 1000\end{array}$ $25 \mathrm{mg} / \mathrm{mlGlu}++++++-++$ carboxy-PTIO +++++++

Figure 5. The effects of a NO scavenger, carboxy-PTIO and NO donors on content of IRS-1 in rat hepatocytes and skeletal myocytes. Rat hepatocytes (a) or skeletal myocytes (b) were treated with the NO-scavenger, carboxy-PTIO $(0.1 \mu \mathrm{M})$ with the indicated concentrations of GSNO or SNAP in the presence the indicated concentrations of insulin, with or without $25 \mathrm{mg} / \mathrm{ml}$ glucose (Glu). Values are expressed as means \pm SEM; $* p<0.05$ vs the insulin-stimulated control $(100 \mathrm{mM}$ insulin).

of the NO donors. Further, these results suggest that the effects of NO inhibition might be reversible if treated early, and before the pathologic sequelae associated with diabetes is evidenced.

Insulin action is initiated through its binding to the cell-surface receptor, initiating a series of signal transduction reactions, which stimulate various effectors to produce its physiological effects. Therefore, impairment of insulin signal transduction results in attenuation of insulin action and leads to insulin resistance resulting in type 2 diabetes mellitus. Because the molecular mechanisms of insulin resistance are still obscure, it is indispensable to establish in vitro models of basal and insulin-mediated signal transduction to elucidate these mechanisms and suggest treatments where appropriate.

$\mathrm{NO}$ and NO-related compounds can function as both protective and cytotoxic, dependent on the cellular context and the nature of the NO group $[17,18]$. The multifaceted actions of the NO group can be classified into true NO-mediated, cGMPdependent, and reactive nitrogen species-mediated, cGMP-independent actions. The cGMP-dependent actions play critical roles in a variety of physiological processes, including NO-mediated vasodilation. In contrast, cGMP-independent, nitrosative protein post-translational modifications, including protein S-nitrosylation and tyrosine nitration are important mechanisms for regulating signal transduction. These reversible reactions are postulated to be involved in the pathological responses [17, 18]. SNAP and GSNO release NO in a quantitative manner, and in the absence of a quenching agent, will produce quantities of NO which will diffuse across the cell membranes and disrupt the normal cellular processes. Some of the differences observed in this study could be attributable to differences in concentration as well as in potency of the NO-releasing capacity of the drugs. However, it appears that there are some environmental influences which suggest 'tissue-specific' activities, possibly due to the different physiological milieus of the cells (tissues) used in this study.

Important recent findings highlight the involvement of S-nitrosylation (or S-nitrosation) of proteins in vesicle-mediated insulin release [19], or of IRS-1 [20] by NO donors. In the latter study [20], as well as another [21], the authors found that the treatment of cultured myocytes with NO donors induced IRS-1 degradation and consequently reduced protein content in a time- and concentration-dependent manner. However, S-nitrosation was implicated as a precursor to IRS-1 degradation only after chronic exposure to GSNO [20]. In the present study, in the absence of measuring S-nitrosation, we noted that acute treatment of skeletal myocytes and hepatocytes by either SNAP or GSNO resulted in a significantly reduced content of available IRS-1 for participating in insulinmediated signal transduction. Prior to the publication by Carvalho-Filho et al. [20], the postulated mechanisms for insulin resistance involved either increased phosphotyrosine phospatase activity or 
increased serine phosphorylation of IRS-1 [22, 23], and only increased or preferential serine phosphorylation of IRS-1 had been linked to insulin resistance mediated by IRS-1 degradation [24, 25]. It is well established that changes in the level of phosphorylation at any of the possible sites on IRS-1 could potentially alter its ability of IRS- 1 to bind and activate the various downstream effectors in the insulin-mediated signal transduction pathway [4]. It is our view that S-nitrosation is secondary to serine phosphorylation as the means whereby NO mediates insulin resistance in skeletal muscle. This is based on the fact that IRS-1 degradation potentiated by S-nitrosation occurs only after chronic in vitro exposure to the NO donor [20], unlike proteasome-mediated degradation subsequent to serine phosphorylation [26]. Whether these NO donors mediate insulin resistance and/or impaired insulinmediated signal transduction via increased serine and/or decreased tyrosine phosphorylation, or via perturbation of other effectors are being investigated in our laboratory.

While some studies suggest that insulin downregulates the expression of IRS-1 [27, 28], we found that this was true only for hepatocytes and skeletal myocytes exposed to high (1000 nM) insulin concentration. However, we noted that IRS-1 expression was significantly enhanced in the presence of $100 \mathrm{nM}$ insulin concentrations in both tissues. This is not unexpected as the tissues and cells used in this study were expressing normal amounts of insulin receptors and would naturally have enhancement of IRS-1 expression when exposed to $100 \mathrm{nM}$ insulin in the presence of glucose. In contrast, those authors $[27,28]$ reported a decrease in IRS- 1 expression after chronic $(12 \mathrm{~h})$ exposure of $\mathrm{CHO}$ cells expressing insulin receptors and IRS-1 due to ubiquitination and degradation of IRS-1. This is also logical as chronic exposure to insulin would mimic insulinresistance, which would lead to internalization of the insulin receptors (a feature seen in acute exposure to high insulin concentrations) and a reduction of available IRS-1 molecules.

Carboxy-PTIO reacts rapidly with NO to yield $\mathrm{NO}_{2}$ and has been increasingly used as a scavenger to test the importance of NO in various physiological conditions. Our data strongly support this thesis, and these findings have been corroborated with studies involving other NO donors, including diethylamine/NO [29], SIN-1 [30], streptozotocin [31], and NOC7 [32].
In conclusion, it is clear that NO released from the NO donors have a negative effect on IRS-1 expression in rat hepatocytes and skeletal myocytes. This reduction would have a direct effect on the number of IRS-1 molecules available for phosphorylation of tyrosine residues and transduction of the insulin signal. Increasing insulin concentrations in this context did not help but rather further reduced the content. Taken together, these results indicate a direct role of $\mathrm{NO}$ in the impairment of insulin-mediated signal transduction in insulin-sensitive tissues, and possibly in the pathogenesis of type 2 diabetes mellitus.

\section{Acknowledgements}

This work was supported by research grants from the Principal's office (New Initiative Fund), and the School of Graduate Studies and Research, University of the West Indies, Mona, Jamaica.

\section{References}

1. Cavaghan M.K., Ehrmann D.A. and Polonsky K.S., Interactions between insulin resistance and insulin secretion in the development of glucose intolerance. J. Clin. Invest. 106: 329-333, 2000.

2. Khan S.E., The importance of $\beta$-cell failure in the development and progression of type I.I. diabetes. J. Clin. Endocrinol. Metab 86: 4047-4058, 2001.

3. DeFronzo R.A., The triumvirate: B-cell, muscle, liver: a collision responsible for N.I.DDM. Lilly Lecture. Diabetes 37: 667-687, 1987.

4. Morris F., White C. and Ronald K., Insulin signaling system. J. Biol. Chem. 269: 1-4, 1994.

5. Culotta E. and Koshlanf D.E. Jr., No news is good news. Science 258: 1862-1865, 1992.

6. DeFronzo R.A., Bonadonna R.C. and Ferrannini E., Pathogenesis of N.I.DDM: a balanced overview. Diabetes Care 15: 318-368, 1992.

7. Ulrich A., Human insulin receptor and its relationship to the tyrosine kinase family of oncogenes. Nature 313: 756-761, 1985.

8. Lane P. and Gross S.S., Cell signaling by nitric oxide. Semin. Nephrol. 19: 215-229, 1999.

9. Gross S.S. and Wolin M.S., Nitric oxide: pathophysiological mechanisms. Annu. Rev. Physiol. 57: 737-769, 1995.

10. Stamler J.S., Janki O. and Osborne J.A., Nitric oxide circulates in mammalian plasma primarily as an S-nitrosoproduct of serum albumin. Proc. Nat. Acad. Sci. USA 89: 7624-7677, 1992.

11. McGrowder D., Ragoobirsingh D. and Dasgupta T., Decreased insulin binding to mononuclear leucocytes and 
erythrocytes from dogs after S-nitroso-N-acetylpenicillamine administration. BMC Biochem. DOI:10.1186/14712091-3-1.

12. Ragoobirsingh D., McGrowder D., Barrett K. and Brown P.D., Direct effect of nitric oxide on basal and insulinstimulated glucose transport in rat skeletal muscle (Abstract). West Indian Med. J. 52((Suppl. 6) 15, 2003.

13. Barrett K., McGrowder D., Brown P.D. and Ragoobirsingh D., Nitric oxide inhibits insulin-stimulated glucose transport in adipocytes (Abstract). West Indian Med. J. 53(Suppl. 2) 52-53, 2004.

14. Freshney R., Culture of animal cells: a manual of basic techniques. Alan R. Liss, Inc, New York, 1987, 117.

15. Bradford M.M., A rapid and sensitive method for the quantitation of microgram quantities of protein, utilizing the principle of protein-dye binding. Anal. Biochem. 72: 248-254, 1976.

16. Rasband W.S. and Image J., U.S. National Institutes of Health, Bethesda, Maryland, USA, http://www.rsb.info.nih.gov/ij/, 1997-2005;2005.

17. Broillet M.C., S-nitrosylation of proteins. Cell Mol. Life Sci. 55: 1036-1042, 1999

18. Foster M.W., McMahon T.J. and Stamler J.S., S-nitrosylation in health and disease. Trends Mol. Med. 9: 160-168, 2003.

19. Stamler J.S., Lamas S. and Fang F.C., Nitrosylation: the prototypic redox-based signaling mechanism. Cell 106: 675-683, 2001.

20. Carvalho-Filho M.A., Ueno M., Hirabara S.M., Seabra A.B., Carvalheira J.B.C., de Oliveira M.G., Velloso L.A., Curi R. and Saad M.J.A., S-nitrosation of the insulin receptor, insulin receptor substrate 1 , and protein kinase $\mathrm{B}$ / Akt: a novel mechanism of insulin resistance. Diabetes 54 959-967, 2005.

21. Sugita H., Sugita M. and Kaneki M., iNOS gene disruption restores depressed I.R.S-1 expression in skeletal muscle and ameliorates insulin resistance in (ob/ob) mice (Abstract). Diabetes 52((Suppl. 1) A299, 2003.

22. Elchebly M., Payette P., Michaliszyn E., Cromlish W., Collins S., Loy A.L., Normandin D., Cheng A., HimmsHagen J., Chan C.C., Ramachandran C., Gresser M.J., Tremblay M.L. and Kennedy B.P., Increased insulin sensitivity and obesity resistance in mice lacking the protein tyrosine phosphatase-1B gene. Science 283: 1544-1548, 1999.
23. Hotamisligil G.S., Peraldi P., Budavari A., Ellis R., White M.F. and Spiegelman B.M., IRS-1-mediated inhibition of insulin receptor tyrosine kinase activity in T.N.F-alpha-and obesity-induced insulin resistance. Science 271: 665-668, 1996.

24. Gao Z., Hwang D., Bataille F., Lefevre M., York D., Quon M.J. and Ye J., Serine phosphorylation of insulin receptor substrate 1 by inhibitor kappa B kinase complex. J. Biol. Chem. 277: 48115-48121, 2002.

25. Liu Y.F., Herschkovitz A., Boura-Halfon S., Ronen D., Paz K., Leroith D. and Zick Y., Serine phosphorylation proximal to its phosphotyrosine binding domain inhibits insulin receptor substrate 1 function and promotes insulin resistance. Mol. Cell Biol. 24: 9668-9681, 2004.

26. Pederson T.M., Kramer D.L. and Rondinone C.M., Serine threonine phosphorylation of I.R.S-1 triggers its degradation: possible regulation by tyrosine phosphorylation. Diabetes 50: 24-31, 2001.

27. Ricort J.M., Tanti J.F., Van Obberghen E. and Le Marchand-Brustel Y., Different effects of insulin and platelet-derived growth factor on phosphatidylinositol 3kinase at the subcellular level in 3T3-L1 adipocytes. A possible explanation for their specific effects on glucose transport. Eur. J. Biochem. 239: 17-22, 1996.

28. Zhande R., Mitchell J.J., Wu J. and Sun X.J., Molecular mechanism of insulin-induced degradation of insulin receptor substrate 1. Mol. Cell Biol. 22: 1016-1026, 2002.

29. Pfeiffer S., Leopold E., Hemmens B., Schmidt K., Werner E.R. and Mayer B., Interference of carboxy-PTIO with nitric oxide- and peroxynitrite-mediated reactions. Free Radic. Biol. Med. 22(5) 787-94, 1997.

30. Ishii M., Shimizu S., Momose K. and Yamamoto T., SIN1 -induced cytotoxicity in cultured endothelial cells involves reactive oxygen species and nitric oxide: Protective effect of sepiapterin. J. Cardiovas Pharmacol. 33: 295-300, 1999.

31. Durán-Reyes G., Pascoe-Lira D., Vilar-Rojas C., MedinaNavarro R., Díaz-Flores M., Ortega-Camarillo C., GarcíaMacedo R., Cruz M. and Rodríguez J.K., Diabetogenic effect of S.T.Z diminishes with the loss of nitric oxide: Role of ultraviolet light and carboxy-PTIO. Pharmacology 71 : 17-24, 2004.

32. Takahashi K., Numata N., Kinoshita N., Utoguchi N., Mayumi T. and Mizuno N., Characterization of the influence of nitric oxide donors on intestinal absorption of macromolecules. Int. J. Pharm. 286: 89-97, 2004. 